\title{
Urban air quality plans in Europe: a review on applied methodologies
}

\author{
A. I. Miranda ${ }^{1}$, C. Silveira ${ }^{1}$, J. Ferreira ${ }^{1}$, A. Monteiro ${ }^{1}$, D. Lopes ${ }^{1}$, \\ H. Relvas ${ }^{1}$, P. Roebeling ${ }^{1}$, C. Borrego ${ }^{1}$, E. Turrini ${ }^{2} \&$ M. Volta ${ }^{2}$ \\ ${ }^{1}$ CESAM and Department of Environment and Planning, \\ University of Aveiro, Portugal \\ ${ }^{2}$ Department of Mechanical and Industrial Engineering, \\ University of Brescia, Italy
}

\begin{abstract}
Air pollution is seen as one of the most pressing problems in many urban areas with serious implications on the environment and human health. Focusing on this critical issue, the 2008 European Air Quality Directive (2008/50/EC) requires European Member States to design appropriate Air Quality Plans (AQP) for zones and agglomerations where the air quality does not comply with the limit/target values.

A review of assessment capabilities and modelling tools used to evaluate the effects of emission abatement measures on the air quality and health has been performed based on a compilation of regional and local AQP. In general, models are applied to estimate emissions and to assess the current air quality and the impact of emission abatement scenarios. Some studies, however, still consider the monitoring network as spatially representative of the study domain and do not include the use of air quality models (e.g. Lisbon Region, Riga, Malta).

At this regional/local scale it is not a common practice to apply a more integrated air quality and health approach based on Integrated Assessment Methodologies (IAM). Notwithstanding, there are some exceptions, such as the AQP of Stockholm, Antwerp, Athens, London and several regions of Italy and Denmark, which integrate the assessment of how reductions in emissions improve air quality, reduce human exposure and protect human health. The costs associated to the effectiveness of emission abatement measures are also included in these IAM contributing to the selection of the most cost-effective abatement measures.
\end{abstract}


This review of AQP modelling practices helps understanding the reasons for the still on-going levels of non-compliance, as well as, evaluating available and commonly used tools to predict the air quality and their effects, contributing to the decision-making process on air quality management policies.

Keywords: urban air quality, European legislation, air quality plans, modelling tools, integrated assessment methodologies.

\section{Introduction}

Nowadays poor air quality is recognized as one of the most pressing problems in urban areas, whose impacts on health and environment are very harmful [1]. The World Health Organization has classified air pollution as carcinogenic to human beings [2]. According to the latest report on air quality in Europe, air pollution implications are mainly due to high levels of particulate matter (PM) and ozone $\left(\mathrm{O}_{3}\right)$ in the atmosphere. Anthropogenic emissions are identified as the greatest contributors to the concentration levels of air pollutants, but atmospheric phenomena occuring at different spatial scales also contribute to the increase of environmental damages [1].

In order to reduce air pollution effects, particularly in cities where the majority of the European population lives, it is important to define effective planning strategies for air quality improvement. For this purpose, Air Quality Plans (AQP) establishing emission abatement measures, previously known as Plans and Programmes, have to be designed and implemented by the Member States (MS) of the European Union (EU) in accordance to the Framework Directive 96/62/EC on ambient air quality assessment and management. Later, in 2008, based on the Framework Directive and in other previously existing legal documents, a new Air Quality Directive (AQD) (Directive 2008/50/EC) was published, introducing new concepts, and simplified and reorganized guidelines. The application of numerical models is highlighted in this new Directive as a fundamental tool to better assess and manage air quality, encouraging their use in the preparation of AQP.

The formulation and implementation of the most appropriate AQP imply the identification of emission sources, assessment of the contribution of these sources to the ambient concentration levels, prioritizing the sources that need to be tackled, and the identification and evaluation of the various improvement options, taking into account their costs, technical feasibility and effects on the environment and human health. Figure 1 presents a simplified scheme showing the different stages of an AQP. Integrated Assessment Methodologies (IAM) have been receiving prominence in the scientific literature (e.g. [3, 4]), because they include cost-benefit/effectiveness analyses of the control options [5], and are an added value to the decision-making process.

The main objective of this study is to perform a literature review of the existing assessment capabilities and modelling tools used by MS to evaluate the effects of local and regional AQP on the reduction of atmospheric pollutant concentrations and human health impacts. Limitations of the currently available 


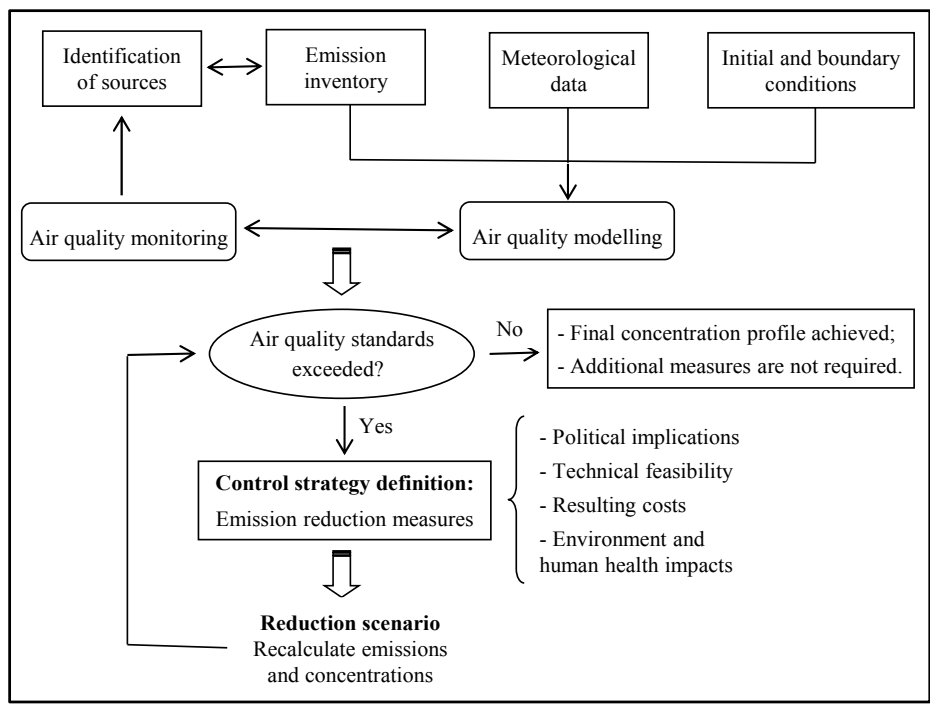

Figure 1: $\quad$ Simplified scheme of the different stages included in an AQP.

assessment methods as well as the identification of best-practices for quantifying the overall impact of the measures are also addressed.

\section{Characterization of the reviewed air quality plans}

The literature review was focused on AQP developed by MS, but also included case studies reported in publications and information obtained from research projects.

\subsection{Overview of the AQP}

Twenty AQP developed by European MS were screened. Table 1 includes the main characteristics of these AQP, namely region/agglomeration and pollutants addressed, as well as the methodologies applied. All AQP contain topics related to emissions and their impacts on air quality and health, although in the vast majority of them only the influence of the emission abatement measures on the air quality is quantified.

Air pollution problems related to particulate matter of aerodynamic diameter less than $10 \mu \mathrm{m}\left(\mathrm{PM}_{10}\right), \mathrm{O}_{3}$, nitrogen oxides $\left(\mathrm{NO} / \mathrm{NO}_{2}\right)$ and sulphur dioxide $\left(\mathrm{SO}_{2}\right)$ are the pollutants most addressed by the AQP. The same conclusion can be extracted from the European Commission (EC) report on Plans and Programmes assessment [6]. In most cases, road traffic was identified as the main source of $\mathrm{PM}_{10}$ and $\mathrm{NO}_{2}$ exceedances, followed by industry, commercial and residential sources. Sulphur dioxide exceedances are only associated to industrial activity.

In relation to the methodological procedures adopted in AQP, the costs for implementation (equipment and maintenance) of the abatement measures and the 
use of air quality modelling tools to evaluate the effects of the measures application are taken into account in the majority of the cases.

Table 1: $\quad$ Main characteristics of some MS AQP.

\begin{tabular}{|c|c|c|c|c|}
\hline $\begin{array}{l}\text { Member } \\
\text { States }\end{array}$ & $\begin{array}{c}\text { Region/ } \\
\text { Agglomeration }\end{array}$ & Pollutants & Methodologies* & References \\
\hline Belgium & Antwerp & $\mathrm{NO}_{2}, \mathrm{PM}_{10}, \mathrm{PM}_{2.5}, \mathrm{SO}_{2}, \mathrm{CO}$ & $1,3,4$ & [7] \\
\hline Denmark & $\begin{array}{l}\text { Copenhagen, Aalborg, } \\
\text { Aarhus and Odense }\end{array}$ & $\mathrm{NO}_{\mathrm{X}}, \mathrm{O}_{3}, \mathrm{PM}_{10}$ and others & $1,3,4$ & [8] \\
\hline France & Marseille and Arles & $\mathrm{NO}_{2}, \mathrm{O}_{3}, \mathrm{PM}, \mathrm{SO}_{2}, \mathrm{CO}$ & 1,3 & [9] \\
\hline Germany & Berlin & $\mathrm{NO}_{\mathrm{X}}, \mathrm{PM}_{10}$ & 1,3 & [10] \\
\hline Greece & Athens & $\mathrm{NO}_{\mathrm{X}}, \mathrm{NMVOC}$ & $1,3,5$ & [11] \\
\hline Ireland & Several regions & $\begin{array}{c}\mathrm{NO}_{\mathrm{X}}, \mathrm{O}_{3}, \mathrm{PM}_{10}, \mathrm{PM}_{2.5} \\
\mathrm{SO}_{2}, \mathrm{CO}, \mathrm{CO}_{2}, \mathrm{VOC} \text { and } \\
\text { others }\end{array}$ & 1,2 & [12] \\
\hline Italy & Several regions & $\begin{array}{l}\mathrm{NO}_{\mathrm{x}}, \mathrm{PM}_{10}, \mathrm{SO}_{2}, \\
\text { Hydrocarbons, Heavy } \\
\text { Metals and others }\end{array}$ & $1,3,4$ & {$[4,13]$} \\
\hline Latvia & Riga & $\mathrm{NO}_{2}, \mathrm{PM}_{10}, \mathrm{PM}_{2.5}$ & 1,2 & [14] \\
\hline Malta & Maltese Islands & $\mathrm{PM}_{10}, \mathrm{NO}_{2}$ & 1,2 & {$[15]$} \\
\hline Netherlands & Several regions & $\begin{array}{l}\mathrm{NOx}, \mathrm{PM}_{10}, \mathrm{SO}_{2} \\
\mathrm{CO}_{2} \text { and others }\end{array}$ & 1,3 & {$[16,17]$} \\
\hline Poland & Several regions & $\mathrm{PM}, \mathrm{NO}_{2}, \mathrm{SO}_{2}, \mathrm{O}_{3}, \mathrm{CO}$ & 1,3 & {$[18]$} \\
\hline \multirow{3}{*}{ Portugal } & Northern Region & $\mathrm{NO}_{2}, \mathrm{PM}_{10}$ & 1,3 & [19] \\
\hline & Braga Agglomeration & $\mathrm{PM}_{10}$ & 1,3 & [20] \\
\hline & $\begin{array}{l}\text { Lisbon and Tagus } \\
\text { Valley Region }\end{array}$ & $\mathrm{NO}_{2}, \mathrm{PM}_{10}, \mathrm{SO}_{2}$ & 1,2 & [21] \\
\hline Romania & Bucharest & $\mathrm{NO}_{2}, \mathrm{O}_{3}, \mathrm{PM}_{10}, \mathrm{SO}_{2}, \mathrm{CO}$ & 1,3 & [22] \\
\hline \multirow{2}{*}{ Spain } & Madrid & $\begin{array}{l}\mathrm{NO}_{2}, \mathrm{O}_{3}, \mathrm{PM}_{10}, \mathrm{SO}_{2} \text { and } \\
\text { others }\end{array}$ & 1,3 & {$[23,24]$} \\
\hline & $\begin{array}{c}\text { Barcelona } \\
\text { metropolitan area }\end{array}$ & $\mathrm{NO}_{2}, \mathrm{PM}_{10}$ & 1,3 & [25] \\
\hline Sweden & Stockholm & $\mathrm{NO}_{\mathrm{X}}, \mathrm{PM}_{10}, \mathrm{CO}_{2}$ & $1,3,4$ & [26] \\
\hline \multirow{2}{*}{$\begin{array}{l}\text { United } \\
\text { Kingdom }\end{array}$} & London & $\mathrm{NO}_{2}, \mathrm{PM}_{10}$ & $1,3,4$ & {$[27,28]$} \\
\hline & Manchester & $\mathrm{NO}_{2}, \mathrm{PM}_{10}, \mathrm{SO}_{2}, \mathrm{CO}$ & 1,3 & [29] \\
\hline
\end{tabular}

*1- Costs for implementation (equipment and maintenance) of abatement measures; 2- Effectiveness of the measures in reducing emissions is assumed to be proportional to benefits on the air quality (using only monitoring indicators); 3- Impact on air quality of designed measures based on modelling (validation with reference observed values); 4- Air quality impacts on the human health; 5- Air quality impacts on both human health and environment. 


\subsection{Methodologies}

This section presents a brief description of the methodologies used in the design of the AQP. These approaches are focused on the emission abatement measures in the sense of assessing their impacts on air quality and health.

\subsubsection{Measures adopted to improve the air quality}

The definition of effective abatement measures can benefit from source apportionment to identify the geographic origin of pollutants and the contribution of sources responsible for the air pollution exceedances. Thus, AQP abatement measures have been focused on the most relevant pollution sources. These measures, classified as technical (TM) and non-technical (NTM), are identified and evaluated, aiming their quantification in terms of reduction efficiency and associated costs of their implementation and operation. From this simplified cost-efficiency analysis, the measures are selected and prioritized for implementation in order to effectively provide a certain benefit [2]. Priority measures are those which were estimated as more effective and with lower total implementation costs. However the costs quantification, particularly related to the proposed long-term measures, tends to have a higher degree of uncertainty for reasons linked with the evolution of the goods and services price that influence this estimation.

In addition to the nature of the measures (TM and NTM), the spatio-temporal horizon for their application is also an important factor to consider. Since the quantification of the measures impact is often conducted at agglomeration scale, the synergy and consistency between measures designed for different spatial levels (national, regional, local or even district) should be ensured.

\subsubsection{Air quality assessment}

The air quality assessment was mainly based on a combination of information from monitoring networks and modelling results. Some AQP, however, only consider the monitoring network as spatially representative of the study domain (e.g. Lisbon Region, Riga, Malta). Nevertheless, as it was mentioned before, the use of models is currently encouraged by the AQD as a tool to support the decision making process and air quality management. They estimate pollutant concentrations in areas not covered by air quality stations, and also for projected emission scenarios. Eulerian Chemical Transport Models (CTM) are the most used, requiring as input data the emissions estimated for the several activity sectors and meteorological variables, normally obtained from mesoscale meteorological models.

The emissions inventory must be as detailed and specific as possible, aiming to contribute to a more correct characterization of the reference situation. Accordingly, bottom-up approaches (e.g. local level - higher detail) should preferably be used. However due to the lack of detailed data to depict smaller territories, top-down emission inventories (e.g. national or even international level) have often been considered. Thus, spatial disaggregation techniques at municipal level or even in the smallest functional units (e.g. parishes) are adopted, using disaggregation factors, such as the population density. The 
comparison of both approaches is recommended in order to test the appropriateness of the spatial and temporal distributions [30], assessing at the same time the consistency across the scales [24].

In terms of meteorology, a comprehensive set of meteorological conditions is desirable to assess how reduction measures work. However, given the models' requirements and computational limitations (e.g. running time), the common practice in AQP is to use meteorological data for a shorter study period. Usually, these data are selected for different seasons, but always in the perspective to support the characterization of air pollution episodes.

The impact of the emission control strategies on the air quality has been assessed using multi-scale models with nesting approach.

Once held the air quality assessment, an important step often neglected in $\mathrm{AQP}$, at least in quantitative terms, is related with the resulting effects (e.g. human health) of the air quality. Thus, based on the analysed publications and in AQP where these effects were quantified, an economic evaluation is presented below.

\subsubsection{Economic evaluation}

The economic analysis allows identifying alternatives/measures to improve the air quality, weighting their consequences or effects against their costs. For this purpose, a comprehensive assessment of all air pollution impacts, also expressed as externalities, is required [2]. Externalities generated from air pollutants are related to the social welfare and economy, and can include both negative economic effects (damages) and positive economic effects (benefits, also described as avoided external costs) on the environment and health [31]. If benefits are larger than costs, the policy or measure is more effective and beneficial for improving air quality. Normally, the comparison of two or more measures is examined through cost-effectiveness and cost-benefit analyses.

The cost-effectiveness assessment (CEA), in accordance to the AQD, is used to compare the relative costs and corresponding air quality and/or heath impact associated with the implementation of measures. Considering the health effects, typically the CEA is expressed in terms of the ratio between a gain in health from a measure (e.g. increased life expectancy) and the cost associated to its implementation. The cost-benefit assessment (CBA) differs from the CEA, because effects (benefits) and costs of the measures are accounted in monetary value. However, this evaluation is not a straightforward procedure since many of the air pollution effects have no market value [32].

Both assessments are based on different approaches, but in scope of this research, emphasis is given to the Externalities of Energy (ExternE) methodology, already applied for Antwerp, Athens, Lisbon and several regions of Denmark. This methodology provides a framework for obtaining impacts expressed in different units (e.g. physical-health effects), following a CEA, which can be converted to a common unit (monetary values) in order to make a CBA [36]. In terms of calculation, the ExternE comprises an Impact Pathway Approach (IPA), which allows to get the exposure of sensitive receptors (e.g. population) using an exposure-response function (e.g. cases of asthma due to 
increase in $\mathrm{O}_{3}$ levels). Then the valuation of these impacts is estimated in monetary terms (e.g. monetary value of an asthma case). The health impacts are highlighted because they contribute to the largest part of the damage estimates. This finding is shared by public health experts, linking the air pollution, even at current ambient levels, to worsening morbidity (especially respiratory and cardiovascular diseases) and premature mortality (e.g. years of lost life) [31]. Estimated costs to the treatment of diseases, including hospitalization and willingness-to-pay are two of the commonly used indicators.

Equation (1) shows the parameterization considered for calculating the emissions impact per air pollutant from a specific source or sector taking into account the abatement measures package included in AQP [11,31].

$$
\Delta \mathrm{I}_{\text {cases }, \mathrm{i}}=\mathrm{CRF}_{\mathrm{i}, \mathrm{p}} \cdot \Delta \mathrm{C}_{\mathrm{p}} \cdot \mathrm{pop}
$$

where:

$\Delta \mathrm{I}_{\text {cases, } \mathrm{i}}$ - Response as a function of the number of the unfavorable implications (cases) over all health indicators $(i=1, \ldots, n)$ avoided or not. The resulting physical impacts are translated to monetary values (damage costs), in order to be properly considered in the decision-making process.

$\mathrm{CRF}_{\mathrm{i}, \mathrm{p}}$ - Correlation coefficient between the pollutant's $p$ concentration variation and the probability of experiencing or avoiding a specific health indicator $i$ (Relative Risk);

$\Delta \mathrm{C}_{\mathrm{p}}-$ Change in the pollutant's $p$ concentration after the adoption of abatement measures (emission scenarios);

Pop - Population units exposed to pollutant $p$.

The pollutants concentration and population data are combined to estimate the human exposure, and then, the impact coefficient $\left(\mathrm{CRF}_{\mathrm{i}, \mathrm{p}}\right)$ is calculated using an exposure-response function (ERF), expressed as Relative Risk (RR) derived from epidemiological studies. Health indicators include all mortality and morbidity effects associated with the exposure to air pollutants, of which a greater significance is attributed to particulate matter [26].

The resulting benefits are often translated on the cost required for the unitary reduction of the emissions of each air pollutant considered. However, a situation which occurs regularly when the available budget is known is the evaluation of the potential emission reduction achieved through the adoption of specific measures [11]. Furthermore, it is also important to note that a CBA does not necessarily correspond to overall effectiveness. For example, a certain project or technology may be very cost-effective at reducing NMVOC in an $\mathrm{O}_{3}$ nonattainment area, but if the project or technology is only applied to very few emission sources, or if the atmospheric chemistry in the $\mathrm{O}_{3}$ nonattainment area is $\mathrm{NO}_{x}$ dependent, the overall effectiveness in reducing $\mathrm{O}_{3}$ may be quite limited.

\subsubsection{Integrated assessment}

In an integrated assessment of the performance of emission abatement measures it is intended to jointly address the environmental and health impacts and to make an economic evaluation of the costs for measures implementation and quantification of damages/benefits. For this purpose, recently local and regional 
IAM have been developed in order to overcome some limitations identified in AQP, particularly in terms of the air quality impacts on health. These IAM tools need data from the emission sources, namely emission inventories and their contribution to atmospheric concentrations and human exposure, but also emission control measures and their costs, in the sense of exploring strategies that permit a reduction of emissions [3]. The great advantage of these tools is the ability to determine the consequences of different assumptions and simultaneously interrelating different factors. Similarly to the air quality models, the efficacy of the IAM is limited by the quality and character of the assumptions and input data $[3,7]$. Taking advantage of the added value of these tools, some European MS have already applied IAM to support the preparation of AQP. Focusing on the reviewed AQP, the AURORA modelling system (Air quality modelling in Urban Regions using an Optimal Resolution Approach) and the USIAM (Urban Scale Integrated Assessment Model) were used in Belgium (Antwerp) and United Kingdom (London metropolitan area), respectively.

The USIAM is an integrated assessment tool developed to quantify the primary $\mathrm{PM}_{10}$ contribution, requiring the integration of information on the sources and pollution imported into the city, atmospheric dispersion and resulting concentrations relative to air quality standards, and costs and benefits of different options for emission reduction. To predict the impact of emission control strategies, USIAM evaluates the implementation of different scenarios [28].

The AURORA system is based on the same principle of USIAM. This modelling tool consists of various modules (e.g. health effects, economical aspects, scenario module and European regulation) [7]. The effects on the health and ecosystems degradation are assessed through dose-response functions using the ExternE methodology [31], and then the costs estimation is performed. A module of scenario analysis allows decision makers determine the best measures to improve the air quality in both quantitative and qualitative ways [7].

\section{Limitations and best-practices for quantifying the measures impact}

The use of models to support the development of AQP is an advantage to characterize atmospheric processes and describe causal relationships, still providing some guidance on the implementation of mitigation measures [33], grounded in cost-effectiveness analyses.

In most cases, the impact of these measures on air quality is assessed using mesoscale air quality modelling systems. Despite a satisfactory performance of these models at the urban scale, weaknesses are identified by the scientific community. For example, strong concentration gradients of $\mathrm{NO}_{2}$, normally associated with high road traffic flows, cannot be reproduced by mesoscale Eulerian models since large concentration variations typically exist within the extension of a grid cell. In order to depict street level concentration gradients, specific and local-scale tools are needed, either high-resolution flow models that consider the buildings or semi-empirical street canyon models able to capture 
this variability. To this respect, Computational Fluid Dynamic (CFD) models are very computationally expensive and can only be applied to spatially and temporally restricted domains.

The integration of models in air quality assessment systems is many times referred as a critical issue, given the lack of consistency between scales. Another important point, rarely addressed in AQP, is related with the air quality in an integrative perspective, which should include an economic analysis of the emission reduction measures, quantifying the total investment and human health and environment effects resulting from exposure levels to certain pollutants. However, the inherent uncertainties in damage estimates, as for any modelling approach, have generated quite controversy regarding the usefulness of damage costs. In response to this critical issue, it is referred that even an uncertainty by a factor of three is better than infinite uncertainty. Other possibility to explore the uncertainties in the context of specific decisions is to carry out sensitivity analyses and check whether the decision (e.g. implementation of technology A instead of technology B) changes for different assumptions (e.g. discount rate, costs per tonne of $\mathrm{CO}_{2}$, valuation of life expectancy loss) [12, 31].

For these reasons, efforts for the development of a consistent and flexible approach that allows determining air quality levels and their impacts at urban/local scale are required. Such methodology must be used to assess the effectiveness of both technical and non-technical measures in different spatial domains in a comprehensive multi-scale system. The effect of synergy between some measures should also be taken into account, due to the fact that different measures jointly implemented might have a greater effect than the sum of the measures applied separately. Moreover, the selection of measures should be guided for the existing operational means, keeping in mind the articulation of measures to develop and the public acceptability of these measures.

Based on the current methodological limitations, some improvements concerning the air quality modelling have been made. However, at emission inventory level, much work still needs to be done, aiming its detailed application at urban atmosphere. This is probably the most relevant critical aspect to characterize air pollution levels in large cities, since an accurate knowledge on emissions from the main sources largely dictates the air quality management policies to adopt. Uncertainties are also related to the way how emissions are put/applied into air quality model as well as with the consistency between emission inventories developed at different scales based on both bottom-up and top-down approaches. Fluctuations in the meteorological conditions also contribute to increase the uncertainly level, which can be reduced if trends of emissions and air quality are compared [17].

From the air quality assessment, the only way to control photochemical and particulate matter pollution is to reduce precursor gases and primary particulate matter emitted through human activities. A fraction of precursor gases is emitted through natural processes and neglecting it when testing a control strategy, as it happens in AQP, could lower its efficiency or even produce adverse effects. 


\section{Final comments}

Given the importance attributed to the urban air quality due to high levels of air pollution observed, emission abatement strategies for improving air quality are mandatory. In this context, a legislative framework has been established, obliging Member States to define air quality plans (AQP) and encouraging the involvement of the local authorities and stakeholders in order to meet the air quality standards within a specified temporal horizon.

In this study, the majority of the analysed AQP just considers the measures impact on the air quality. The link between the resulting air quality state and its consequences for the health, despite its unanimously recognized importance by the scientific community, is often neglected, principally in a quantitative way.

Regarding the air quality assessment, the use of models, complementary to monitoring, is viewed as the best currently available tool to understand the response of the atmosphere against different air pollution control measures, providing essential information on the maximum feasible air quality improvement.

Taking into account the limitations of the currently available assessment methods as well as the best-practices identified for quantifying the overall impact of the measures, the path to follow in future AQP studies should be grounded in integrated assessment methodologies, constituting these tools an added value for the decision making process on air quality management.

\section{Acknowledgements}

The authors acknowledge the financial support of FEDER through the COMPETE Programme and of national funds from FCT - Science and Technology Portuguese Foundation in the scope of MAPLIA Project (PTDC/AAG-MAA/4077/2012) and the post doc grants of J. Ferreira (SFRH/BPD/40620/2007) and A. Monteiro (SFRH/BPD/63796/2009). This work has also been done in the scope of the research project APPRAISAL (FP7 Grant Agreement number 303895).

\section{References}

[1] EEA - European Environment Agency, Air quality in Europe - 2013 report, EEA Report. № 9/2013, Copenhagen, 2013.

[2] WHO - World Health Organization, Health risks of air pollution in Europe - HRAPIE project: Recommendations for concentration-response functions for cost-benefit analysis of particulate matter. ozone and nitrogen dioxide. WHO Regional Office for Europe, Copenhagen, 2013.

[3] Carnevale, C., Finzi, G., Pisoni, E., Volta, M., Guariso, G., Gianfreda, R., Maffeis, G., Thunis, P., White, L. \& Triacchini, G., An integrated assessment tool to define effective air quality policies at regional scale. Environmental Modelling \& Software, 38, pp. 306-315, 2012.

[4] D’Elia, I., Bencardino, M., Ciancarella, L., Contaldi, M. \& Vialetto, G., Technical and non-technical measures for air pollution emission reduction: 
the integrated assessment of the regional air quality management plans through the Italian national model. Atmospheric Environment, 43, pp. 6182-6189, 2009.

[5] Amann, M., Bertok, I., Borken-kleefeld, J., Cofala, J., Heyes, C., Höglundisaksson, L., Klimont, Z., Nguyen, B., Posch, M., Rafaj, P., Sandler, R., Schöpp, W., Wagner, F. \& Winiwarter, W., Cost-effective control of air quality and greenhouse gases in Europe: modeling and policy applications. Environmental Modelling \& Software, 26(12), pp. 1489-1501, 2011.

[6] Nagl. C., Moosmann. L. \& Schneider. J., Assessment of plans and programmes reported under 1996/62/EC - final report, Umweltbundesamt GmbH. Vienna, Austria, 2007.

[7] Mensink, C., Colles, A., Janssen, L. \& Cornelis, J., Integrated air quality modelling for the assessment of air quality in streets against the council directives. Atmospheric Environment, 37(37), pp. 5177-5184, 2003.

[8] DCE - Danish Centre for Environment and Energy, The Danish air quality monitoring programme - annual summary for 2012, DCE Scientific Report 67, Denmark, 2013.

[9] FRANCE, Plan de Protection de l'Atmosphère des Bouches-du-Rhône, Révision 2013, France, 2013.

[10] Lutz, M., The low emission zone in Berlin - results of a first impact assessment. Workshop on "NOx: Time for Compliance", Nov. 2009, Birmingham, United Kingdom, 2009.

[11] Tourlou, P.M., Sahm, P. \& Moussiopoulos, N., Integrated assessment of air pollution abatement strategies in urban areas: application to the greater Athens area. Water, Air and Soil Pollution, 2(5-6), pp. 731-744, 2002.

[12] EPA - Environmental Protection Agency, Air Quality in Ireland 2012 Key Indicators of Ambient Air Quality, Ireland, 2013.

[13] ITALY, National Action Plan for Italy, Document prepared for the Mediterranean Action Plan in the framework of the Strategic Action Plan (SAP), Italy, 2005.

[14] ECOREGION, Riga City Air Quality Improvement Action Programme 2011-15: on the possibilities to reduce pollution (particulate matter and nitrogen oxides) and to improve air quality in Riga, Prepared within the framework of INTERREG IVB project "Baltic Sea Region Cooperation Network project - EcoRegion” by Riga City Council, Latvia, 2011.

[15] MEPA - Malta Environment and Planning Authority, Air Quality Plan for the Maltese Islands, Malta, 2010.

[16] NEAA - Netherlands Environmental Assessment Agency, Policy research programme on particulate matter: main results and policy consequences, Publication of the Netherlands Research Program on Particulate Matter, Netherlands, 2010.

[17] Air4EU - Air Quality Assessment for Europe: from local to continental scale, Individual case study report: trend analysis of $\mathrm{NO}_{2} / \mathrm{NO}_{x}$ and $\mathrm{PM}_{10}$ exceedance of daily limit values in Rotterdam, Netherlands, 2006.

[18] Kaminski, J.W. \& Struzewska, J., High resolution operational air quality forecast for Poland and Central Europe with the GEM-AQ model: 
EcoForecast System. Geophysical Research Abstracts, 15, EGU201310197, 2013.

[19] CCDR-N - North Regional Coordination and Development Commission, Plan to Improve Air Quality in the Northern Region, Portugal, 2007.

[20] CCDR-N - North Regional Coordination and Development Commission, Plan to Improve Air Quality in the Braga Agglomeration 2005-2008, Portugal, 2010.

[21] CCDR-LVT - Lisbon Regional Coordination and Development Commission, Plans and Programmes to Improve Air Quality in the Region of Lisbon and Tagus Valley, Portugal, 2006.

[22] ROMAIR, Implementation of an air quality modelling and forecasting system in Romania, www.romair.eu

[23] MADRID - Área de Gobierno de Medio Ambiente, Seguridad y Movilidad, Madrid's Air Quality Plan 2011-2015, Spain, 2012.

[24] Borge, R., Lumbreras, J., Pérez, J., de la Paz, D., Vedrenne, M., de Andrés, J.M., \& Rodríguez, M.E., Emission inventories and modeling requirements for the development of air quality plans. Application to Madrid (Spain). Science of the Total Environment, 466-467, pp. 809-819, 2014.

[25] Soret, A., Jiménez-Guerrero, P. \& Baldasano, J.M., Comprehensive air quality planning for the Barcelona Metropolitan Area through traffic management. Atmospheric Pollution Research, 2(3), pp. 255-266, 2011.

[26] EHA, Environment and Health Administration, The Stockholm Trial: Effects on air quality and health, Sweden, 2006.

[27] DEFRA - Department for Environment, Food and Rural Affairs, Air Quality Plans for the achievement of EU air quality limit values for nitrogen dioxide (NO2) in the UK, Technical Report, London, United Kingdom, 2011.

[28] Mediavilla-Sahagún, A., Apsimon, H. \& Warren, R., Integrated assessment of abatement strategies to improve air quality in urban environments, the USIAM model. Water, Air and Soil Pollution: Focus, 2(5-6), pp. 689-701, 2002.

[29] SCC - Salford City Council, Greater Manchester LTP2 Air Quality Strategy \& Action Plan, Manchester, United Kingdom, 2006.

[30] EEA - European Environment Agency, Air pollution at street level in European cities, EEA Technical report. N ${ }^{\circ} 1 / 2005$, Copenhagen, Denmark, 2006.

[31] European Commission, ExternE Externalities of Energy - Methodology 2005 Update, Office for Official Publications of the European Communities, Edited by Peter Bickel and Rainer Friedrich, EUR 21951 EN, 270 pp., 2005.

[32] Belhaj, M. \& Fridell. E., External Costs in the Transport Sector: A Literature Review, The Swedish Environmental Research Institute, Stockholm, Sweden, 2010.

[33] Daly, A. \& Zannetti, P., Air Pollution Modeling: An Overview (Chapter 2). Ambient Air Pollution, Published by The Arab School for Science and Technology and The EnviroComp Institute, 2007. 